\title{
Selection of Marine Patrol Organizing System: A Case Study for Indonesia
}

\author{
Achmad Farid Wadjdi $^{\mathrm{a}^{*}}$, Agus Rustandi ${ }^{\mathrm{b}}$, Daryono ${ }^{\mathrm{c}}$ \\ ${ }^{a, b, c}$ Researchers of R\&D Agency, Ministry of Defense, Indonesia \\ afarid.wajedi@kemhan.go.id
}

\begin{abstract}
Disagreements among experts in organizing marine security patrols whether a single or multi-agency system is an interesting question. So, this study focused on the problem and investigation of important factors to support decision making. The data collected and explored through focus group discussions and then analyzed using Fuzzy Analytic Hierarchy Process (Fuzzy-AHP) and Dominance-Based Rough Set Approach (DRSA). The results not only show that a single agency system is more critical in managing marine patrol operations in Indonesia, but it also explores the underlying factors as evidence in such a way that it becomes an essential ingredient in formulating a solution strategy. Finally, we recommend a further analysis through other approaches, since there is evidence shown that multi-agency system is still an exciting alternative for marine patrol system.
\end{abstract}

Keywords: DRSA; Fuzzy-AHP; Marine security patrol; Multicriteria decision analysis

\section{Introduction}

In Indonesia's perspective, the sea is the liaison and unifying of the islands. These conditions provide many advantages such as national and international shipping traffic. Meanwhile, geographical constellations with many islands and straits also have potential vulnerabilities and conflicts, such as piracy, theft of marine wealth, people smuggling, human trafficking, illegal fishing, and other threats that impact national security (Forbes 2014). Indonesia has ten maritime borders with neighboring countries, namely: Malaysia, PNG, East Timor, Palau, India, Australia, Philippines, Singapore, Vietnam, and Thailand. Therefore, in the sea border areas, there is potential for security threats that could include environmental violations and sovereignty as well as illegal activities that have a disruptive effect on national stability (Anwar 2006). Today, the crime mode at sea is increasingly involved, so it requires not only coordinated management to be more efficient but also needs support in various ways (Siswanto 2015).

In Indonesia, the management of marine security patrol is carried out by several agencies. The existence of overlapping authority among the agencies in charge of securing the marine areas is a matter of supervisory and operational management that must be appropriately solved. The question that arises is whether the selected single agency will eliminate the function of the marine patrol that currently held by many organizations. If it is still multi-agency, how to set so that each service does not overlap? (Siswanto, 2015).

In this paper, we will discuss the organizing patrol issues with a multi-criteria decisionmaking approach to understanding the most important decision criteria. We hope that this 
approach will complement the existing literature on the discourse of marine safety patrol management that uses descriptive qualitative approaches.

\section{Literature review}

There are many studies and expert opinions related to the selection of multi or single agency systems of marine patrol (Chapsos and Malcolm 2017; Collin 2016; Febrica 2015; Keliat 2009; Li and Cheng 2007; Parameswaran 2016). The discourse of agency system on marine security patrol is related to two approaches: a security approach for a single agency system and a prosperity approach for a multi-agency system(Kemenkeu 2014). In a security approach, there will be only one agency (a single agency system) where its primary function is the function of security and sovereignty, while other features are secondary. In contrast, the prosperity approach will involve many agencies in law enforcement of the sea according to the portion of authority. Paper presented by representatives of Indonesia's finance ministry on focus group discussion recommends a multi-agency system because the prosperity approach is more important than the security approach to Indonesia's current situation and condition. And in fact, in the face of increasing threat, the multi-agency system currently operating in Indonesia, its effectiveness has been much complained (Siswanto 2015).

The best practice of a single agency system is Malaysia, Sweden, Vietnam, Sri Lanka, United States and others. The advantages of the system are simple, straightforward, and a sound command system. While the deficiency is the dispute of administrative, management, and juridical responsibility, and not guaranteed to be free from corrupt practices. While best practices of multi-agency systems are Indonesia, Argentina, South Korea, France, Australia, and others. The advantages of the multi-agency systems are related to clear administrative, management, and juridical accountability (by individual agencies). While the disadvantage is that there is often overlapping implementation of marine law enforcement when implemented by more than one office, especially when there are inconsistencies of regulations, or procedures and mechanisms that are not clear (Guilfoyle 2017).

Factors that influence Marine Patrol Management

Investigations of various factors related to the effectiveness of coordinated marine patrols can be inferred from the multiple research results associated with it. For example, the law is not clear; the overlapping of authority among agencies in securing large areas; and the lack of facilities or infrastructure to support the implementation of patrols. A survey conducted by 'Balitbang Kemhan' (R\&D Agency of MoD Indonesia) found other factors in conducting maritime security patrols, such as the absence of regulations governing coordinated patrols; insufficient personnel power, adequate funds, and vessels; and unsupported security culture (Balitbang Kemhan 2016).

Indeed, each agency does coordinated patrol agreements with neighboring countries, such as Malaysia, Singapore, Philippines, Thailand, and Australia. Unfortunately, most organizations have not yet involved other agencies, still coordinating according to its interests, this behavior indicates that there is a sectoral interest to be accommodated, as well as 
differences in doctrine or standards of operations and procedures that need to be formulated and applied.

In the context of multi-agency systems, the ineffectiveness of patrols due to limited facilities in both quantity and size (Lobo 2005), and budget constraints (Peterson 2010), especially for the procurement of defense and logistics equipment (Caifa 2016) is still a significant obstacle. An onboard patrol using a naval vessel is a form of joint patrol involving two or more agencies and focuses on accelerating the process of handling lawlessness at sea. The onboard patrol always gets recommendations to apply, and to that end, they recommend the formation of coordinated patrol troops by involving various elements. This Task Force must be protected by law (Gilpin 2007). Also, they recommend the establishment of a support agency which has functions in collecting, processing and distributing of marine information (Davis 2006). The support agency must be equipped with support facilities. Additional suggestions that surfaced throughout the patrol activities include the need to define agency responsibilities, increased understanding of each mandate, the prioritization of resource allocation, improvement in interpersonal relationships among agency members, and an efficient and streamlined public engagement procedure (Balitbang Kemhan 2016). Meanwhile, other researchers also provide evidence about difficulties, such as difficulties in sharing information and coordination (Tarmidi et al 2014). Roberts (2017) discussed the insufficient operational budget. Kinney (2009) and Psarros et al (2011) found the lack of personnel and the complex facing threat. Kittinger et al (2011) focus on marine patrol culture. Izurieta et al (2011) underline the significance of relationships, capacities, skills, communication, and cross-cultural information sharing. Those factors will be used as parameters in the analysis to support decision making.

Several methods of decision-making support in the field of marine security have been used (Z. L. Yang et al 2009). In the following sections, it will briefly review the literature related to the methods used in this study.

\section{Application of Fuzzy Analytic Hierarchy Process (Fuzzy-AHP)}

Fuzzy-AHP is a popular method used in supporting decision making in the field of marine security and related management, for examples (Jiasheng et al 2014), (Kambiz, 2011), and (Ramos et al 2011). The use of fuzzy-AHP provides many advantages when there is uncertainty, vague, and subjective nature of trust (Ashtiani \& Abdollahi Azgomi 2015). In this paper, we do not provide a mathematical description of the Fuzzy-AHP method because of the abundance of literature that has explained about it. The general steps of the Fuzzy-AHP approach are inferred from (Jiasheng et al 2014; Kambiz 2011; Ramos et al 2011).

Application of the Rough Set Theory

The Rough Set Theory (RST) introduced by Munakata \& Pawlak (1996) and Pawlak (1998) has proven to be widely used and developed as a tool in multi-criteria decision making (MCDM). Sil et al (2013) used the method in the field of machine learning. Jato-Espino \& Canteras-Jordana (2014) used it in the civil engineering field. Namdeo \& Jyoti (2014) implemented the technique in data mining, and also Lee et al (2014) in health sciences. In handling the inaccuracy or unclear information, RST allows the decision makers to disclose a correct and objective evaluation and can control a bunch of information that is vague and 
subjective at the same time (Q. Yang et al 2017). The main problem in decision making using the classic RST approach is the inconsistency (Szeląg et al 2014), ranking problems, and monotonicity (Błaszczyński et al 2013). The solution is called the Dominance Based Rough Set Approach (DRSA) which permits to deal with inconsistencies typical to consideration of criteria and preference-ordered decision classes, and it has been adapted to a wide range of decision issues, including multi-criteria ranking issues. One of the rule induction algorithm for dominance-based rough set approach is VC-DomLEM (Szeląg et al 2014), and (Błaszczyński et al. 2013), which generates minimal set of rules.

\section{Methodology}

The following framework is used to answer this research question: literature review, comparative analysis of best practice and factor identification through focus group discussions (FGD), and combined Fuzzy-AHP and DRSA analysis. The research design framework is carried out with the following steps:

(i) The influencing factors are assessed based on literature.

(ii) Identifiable influencing factors are confirmed and discussed by all participants through the FGD.

(iii) Essential elements are analyzed using Fuzzy-AHP and DRSA to group decision making.

(iv) Finally, the results of FGD, Fuzzy-AHP, and DRSA are discussed to recommend agency options whether single or multi-agency in the implementation of marine patrols.

The FGD is useful for exploring people's knowledge and experiences and can be used to examine what, how, and why people think that way (Hvitfeldt-Forsberg et al 2017; Pohl et al 2015). The members of FGD discussed the ten factors derived from the literature. The elements are about the type and level of threat in the patrol area, patrol regulations or standard operations applied, the coordination and information sharing, the operational culture of joint patrols, and the availability of patrol boats, personnel, facility, budget, and logistic support.

We conducted five FGD during April to October 2016 in five locations, namely Tanjung Pinang, Batam, Sabang, Ambon, and Kupang. Total FGD participants were 55 experts representing 13 government agencies related to marine patrol operations. We recorded each of the responses and ideas, categorized and discussed in the overall analysis of this research. We distribute the resume of the registered document at random to 13 personnel of FGD's participant as guidance in filling out the form of Fuzzy-AHP and DRSA. Table 1 shows the compositions of factors influencing marine patrol that we inferred from literature. 
Table 1. Factors Affecting Marine Patrol

\begin{tabular}{|c|c|c|}
\hline Component & Factor & References \\
\hline Mission & $\begin{array}{l}\text { - regulatory } \\
\text { - threat }\end{array}$ & (Boots 2009) \\
\hline Patrol Norm & $\begin{array}{l}\text { - } \text { culture } \\
\text { - } \text { coordination } \\
\text { - information }\end{array}$ & (Izurieta et al 2011; Kittinger et al 2011; Tarmidi et al 2014) \\
\hline Capability & $\begin{array}{ll}\text { - } & \text { vessels } \\
\text { - } & \text { skill } \\
\text { - } & \text { facility }\end{array}$ & $\begin{array}{l}\text { (Balitbang Kemhan 2016; Carolin 2007; Hozairi et al 2014; } \\
\text { Paget 2016), (Hopcroftet al 2006) }\end{array}$ \\
\hline Support & $\begin{array}{l}\text { - } \text { budget } \\
\text { - } \text { logistic }\end{array}$ & (Balitbang Kemhan 2016; Roberts 2017) \\
\hline
\end{tabular}

To measure the critical relative factors in this study, we use a framework of Fuzzy-AHP suggested by (Buckley 1985). At last, we used DRSA approach that recommended by (Błaszczyński et al 2013).

\section{Result and Discussion}

During FGD, factors influencing marine patrols have been discussed, see Table 1. Discussion results in five FGD locations suggested establishing of integrated patrols and regulations. Almost all regions stated that the current constraints are the lack of budget allocations, logistics, personnel and ship shortages in both the number and size regarding threat complexity, areal extent, and range of patrol missions.

Discussion on the importance of the integrated patrols, the majority of participants suggested establishing a task force composed of representatives from all maritime security agencies. There are two inferences: First, they require that the maritime security is still carried out in a multi-agency manner; second, to minimize the patrol barriers, they recommend a joint patrol.

We show the final weight of each component calculated using Fuzzy-AHP in Table 2 and the final crisp weight of each factor in Table 3. 
Table 2. Final Weight of Components

\begin{tabular}{|l|l|l|}
\hline Component & Final Fuzzy Weight & Final Crisp Weight \\
\hline Mission & $(0.249 ; 0.573 ; 1.181)$ & 0.644 \\
\hline Support & $(0.106 ; 0.259 ; 0.678)$ & 0.326 \\
\hline Capability & $(0.049 ; 0.115 ; 0.313)$ & 0.148 \\
\hline Patrol Norm & $(0.029 ; 0.053 ; 0.137)$ & 0.068 \\
\hline
\end{tabular}

$\mathrm{CI}^{\mathrm{m}}=0.042 \mathrm{CI}^{\mathrm{g}}=0.023$

Table 3. Matrix of Final Weights of Factors

\begin{tabular}{|l|l|l|}
\hline Factor & Final Fuzzy Weight & Final Crisp Weight \\
\hline Threat & $(0.17 ; 0.504 ; 1.3)$ & 0.619 \\
\hline Budget & $(0.007 ; 0.226 ; 0.765)$ & 0.322 \\
\hline Skill & $(0.013 ; 0.073 ; 0.44)$ & 0.150 \\
\hline Regulatory & $(0.026 ; 0.07 ; 0.199)$ & 0.091 \\
\hline Vessels & $(0.005 ; 0.03 ; 0.23)$ & 0.074 \\
\hline Coordination & $(0.007 ; 0.034 ; 0.192)$ & 0.067 \\
\hline Logistic & $(0.011 ; 0.033 ; 0.125)$ & 0.050 \\
\hline Information & $(0.003 ; 0.014 ; 0.099)$ & 0.032 \\
\hline Facility & $(0.003 ; 0.012 ; 0.093)$ & 0.030 \\
\hline Culture & $(0.002 ; 0.005 ; 0.04)$ & 0.013 \\
\hline
\end{tabular}

Table 4. Matrix of Final Weight of Alternatives

\begin{tabular}{|l|l|l|l|}
\hline Component & $\begin{array}{l}\text { Final Fuzzy Weight of } \\
\text { Alternatives }\end{array}$ & $\begin{array}{l}\text { Final Crisp Weight } \\
\text { of Alternatives }\end{array}$ & $\begin{array}{l}\text { Prioritization Based on } \\
\text { Crisp Weight }\end{array}$ \\
\hline Single Agency & $(0.203,0.832,3.881)$ & 1.437 & 1 \\
\hline Multi Agency & $(0.037,0.168,1.276)$ & 0.412 & 2 \\
\hline
\end{tabular}

Reviewing the weights across all factors in Table 3, we can see that the weight of threat (0.619), budget (0.322), and skilled personnel (0.150) have the highest rankings. The consistency rate $(\mathrm{CR})$ concerning the goal was $0.023<0.1$, then the output of the pairwise comparison can be proven sufficiently consistent (Rabbani \& Bahadornia 2013). The obvious inference is the choice of a single agency system of the marine patrol strongly influenced by high threat levels, low budget support, and inadequate personnel skill capacity. 
The results of DRSA using the VC-DomLEM algorithm are summarized in Table 5, that further explains the conditions of each location in conducting a marine patrol. In Tanjung Pinang, the result shows that the implementation of patrols at least with a multi-agency system due to sufficient personnel skills conditions, or with a single agency system when shelter regulations and operating standards are available. While in Batam the choice of single agency or multi-agency is considered highly dependent on the coordination factor.

Table 5. The Result of DRSA (VC-DomLEM)

\begin{tabular}{|l|l|l|l|l|}
\hline Location & Union Name & Accuracy & Cardinality & Rules \\
\hline \multirow{2}{*}{$\begin{array}{l}\text { Tj. } \\
\text { Pinang }\end{array}$} & at most single & 0.333 & 5 & Regulatory $<=$ very low \\
\cline { 2 - 6 } & at least multi & 0.636 & 8 & Skill $>=$ medium \\
\hline \multirow{3}{*}{ Batam } & at most single & 1 & 4 & Coordination $<=$ low \\
\cline { 2 - 6 } & at least multi & 1 & 9 & Coordination $>=$ medium \\
\hline \multirow{3}{*}{ Ambong } & at most single & 1 & 10 & $\begin{array}{l}\text { Culture }<=\text { low or regulatory }<=\text { very } \\
\text { low }\end{array}$ \\
\cline { 2 - 6 } & at least multi & 1 & 3 & $\begin{array}{l}\text { Culture } \\
\text { coordination }>=\text { very low }\end{array}$ \\
\cline { 2 - 6 } & at least multi & 1 & 2 & Skill $<=$ low \\
\hline \multirow{2}{*}{ Kupang } & at most single & 1 & 9 & Vessel $>=$ low \\
\cline { 2 - 5 } & at least multi & 1 & 4 & Vessel $<=$ very low $>$ low \\
\hline
\end{tabular}

Table 5 also shows that three locations (Sabang, Ambon, and Kupang) recommend patrols with a single agency system and two sites ( $\mathrm{Tj}$ Pinang and Batam) suggest a multi-agency system. In the discussion there are some researchers arguing that the system of many agents in the patrol is still fit by the present conditions. They proposed another method of validating the results of the analysis, for example by the Shafer Dempster approach as used by (Zhou et al 2017), and especially when faced with budget allocation issues (Kemenkeu 2014). They also underline the evidence of two study area is the evidence. The cumulative analysis in each study area shows that although the budget is still a problem, the most urgent solution is not. Sabang sees culture, regulation, and coordination as the most influential factors; Ambon is more concerned with the availability of patrol boats and the capacity of personnel and skill, and so it is with Kupang which emphasizes the importance of ships availability.

The allegations arose from this study that there is an agency's powerlessness behavior due to the deficiencies. When the government established Bakamla as a coordinating agency in maritime security, they immediately felt a growing sense of helplessness. The opinions of those who approved the patrol were made through the establishment of a task force that involved all the roles of the agency, in fact, they felt more considerable doubt about their next position in the patrol. They want a role guarantee. This behavior is in line with what (Desai 
2016) emphasizes that in high risk, there is a tendency for agencies to collaborate with regulatory agencies. It may also be a win-win solution that can satisfy the pro and anti patrol task force using their full engagement in the task force, or at least, adjusting to the needs, patrols should be done periodically (integrated patrol) on a regular basis.

Furthermore, the results of this study also inspire us that the decision-making of the patrol system, if only based on the expert opinion of the subjects, is not enough. It is possible that a conflict will arise. Nevertheless, the results of this study have shown essential criteria and trends toward the two available alternatives. However, to ensure a more profound solution, we recommend the need for a review using other approaches, such as the Advocacy Coalition Framework (Pierce et al 2017; Weible \& Sabatier 2007), the Shafer Dempster approach, and Belief Function Theory (Tacnet et al 2017; Zhou et al 2017).

Referring to the recommendations of this study, we can ignore the choice of single agency systems or multi-agency systems as we place more emphasis on the importance of understanding the factors affecting patrols, rather than on both systems choices. In other words, whatever the decision, they must still have the power to carry out effective marine patrols. Moreover, for that, those factors should be the attention of all parties. The critical element of marine patrol operation in each study location becomes clear, and it can be formulated into strategic recommendations to improve the implementation of marine patrol operations. Thus, the combined use of MCDM and its application in the choice of maritime patrol system remains useful primarily because it can produce an overview of the factors that affect in each locus.

The fact is that DRSA results show that there is two research locus (Tanjung Pinang and Batam) that prefer multi-agency systems, and the other three regions (Sabang, Ambon, and Kupang) prefer single agency system. After discussions among the research teams, we recommend investigating further concerning broader combine theories in the context of MCDM, such as Advocacy Coalition Framework, Shafer Dempster approach, and Belief Function Theory.

\section{Conclusion}

The choice of a single agency system in marine patrol operations is more gained participant support, primarily referring to high levels of threat. However, the option of a multi-agency mode is also supported if controlled conditions are available, adequate budget support, availability of ships, and personnel capacity compliance. The issue of patrol operations in each region varies. However, the four most influential factors are high threat levels, inadequate regulations, low budgets, and lack of skilled personnel.

\section{References}

Anwar, Dewi Fortuna. (2006). "Resource Issues and Ocean Governance in Asia Pacific: An Indonesian Perspective.” Contemporary Southeast Asia 28(3): CS28-3f. http://bookshop.iseas.edu.sg/bookmarks/CS28_3/006/index.html.

Ashtiani, Mehrdad, and Mohammad Abdollahi Azgomi. (2015). "A Multi-Criteria DecisionMaking Formulation of Trust Using Fuzzy Analytic Hierarchy Process." Cognition, 
Technology \& Work 17(4): 465-88.

http://search.ebscohost.com/login.aspx?direct=true\&db=psyh\&AN=2014-43721$001 \&$ site $=$ ehost -

live\%5Cnazgomi@iust.ac.ir\%5Cnm_ashtiani@comp.iust.ac.ir\%5Cnhttp://link.springer. com/10.1007/s10111-014-0310-2.

Balitbang Kemhan. (2016). Efektifitas Patroli Terkoordinasi Di Perbatasan Laut Dalam Rangka Menanggulangi Ancaman Non Militer. kemhan.go.id.

Błaszczyński, Jerzy et al. (2013). Rough Sets and Intelligent Systems-Professor Zdzisław Pawlak in Memoriam jMAF-Dominance-Based Rough Set Data Analysis Framework.

Boots, DP. (2009). "US Border Patrol Critical Issues in Policing: 21st Century Challenges in the National Border Patrol Strategy1." Policing 3(3): 231-44.

http://policing.oxfordjournals.org/content/3/3/231.short.

Buckley, J. J. (1985). "Ranking Alternatives Using Fuzzy Numbers.” Fuzzy Sets and Systems 15(1): $21-31$.

Caifa, Tom. (2016). Lake George Marine Patrol — Proudly Serving the Boating Public since 1962. New York State Conservationist (70): 15-18.

Carolin, Liss. (2007). The Privatisation of Maritime Security-Maritime Security in Southeast Asia: Between a Rock and a Hard Place? perth. http://www.murdoch.edu.au/Researchcapabilities/Asia-Research-Centre/_document/working-papers/wp141.pdf (October 9, 2017).

Chapsos, Ioannis, and James A. Malcolm. (2017). "Maritime Security in Indonesia: Towards a Comprehensive Agenda?" Marine Policy 76: 178-84.

Collin, Koh Swee Lean. (2016). "The Malacca Strait Patrols: Finding Common Ground." RSIS Commentary (91). https://www.rsis.edu.sg/wpcontent/uploads/2016/04/CO16091.pdf.

Davis, Joel D. (2006). MARITIME SECURITY AND THE STRAIT OF MALACCA : A STRATEGIC ANALYSIS. the US Army Command and General Staff College.

Desai, Vinit M. (2016). Under the Radar: Regulatory Collaborations and Their Selective Use to Facilitate Organizational Compliance. Academy of Management Journal 59(2): 63657.

Febrica, Senia. (2015). Why Cooperate? Indonesia and Anti-Maritime Terrorism Cooperation. Asian Politics and Policy 7(1): 105-30.

Forbes, Vivian Louis. (2014). Indonesia's Delimited Maritime Boundaries. Indonesia's Delimited Maritime Boundaries: 1-266.

Gilpin, Raymond. (2007). Enhancing Maritime Security in the Gulf of Guinea Strategic Insights, Volume VI, Issue 1 ( January 2007 ) Threats and Vulnerabilities in the Gulf of Guinea' S Maritime Domain. Strategic Insights VI(1).

Guilfoyle, Douglas. (2017). "Maritime Law Enforcement Operations and Intelligence in an Age of Maritime Security." International Law Studies 93.

http://stockton.usnwc.edu/cgi/viewcontent.cgi?article=1708\&context=ils.

Hopcroft, Robyn, Eleanore Burchat, and Julian Vince. (2006). "Unmanned Aerial Vehicles for Maritime Patrol: Human Factors Issues.” Science And Technology: 1-43. 
http://www.dtic.mil/cgi-

bin/GetTRDoc?AD=ADA454918\&amp;Location=U2\&amp;doc=GetTRDoc.pdf.

Hozairi, Buda Artana Ketut, A A Masroeri, and M Isa Irawan. (2014). The Combination

Method of NSGA-II and Fuzzy C-Means For Distribution Optimization Navy Patrol

Boats. In Seminar on Intelligent Technology and Its Applications, , 2-9.

Hvitfeldt-Forsberg, Helena et al. (2017). "Staffs' and Managers' Perceptions of How and

When Discrete Event Simulation Modelling Can Be Used as a Decision Support in

Quality Improvement: A Focus Group Discussion Study at Two Hospital Settings in

Sweden.” BMJ Open 7(5): e013869.

http://bmjopen.bmj.com/lookup/doi/10.1136/bmjopen-2016-013869.

Izurieta, Arturo et al. (2011). Developing Indicators for Monitoring and Evaluating Joint

Management Effectiveness in Protected Areas in the Northern Territory, Australia.

Ecology and Society 16(3): 22.

Jato-Espino, Daniel, and Juan Carlos Canteras-Jordana. (2014). A Review of Application of

Multi-Criteria Decision Making Methods in Construction. Automation in Construction

45: $151-62$.

Jiasheng, Wang et al. (2014). "Safety Assessment of Shipping Routes in the South China Sea

Based on the Fuzzy Analytic Hierarchy Process." Safety Science 62: 46-57.

http://www.embase.com/search/results?subaction=viewrecord\&from=export\&id=L3697

01314\%0Ahttp://dx.doi.org/10.1016/j.ssci.2013.08.002.

KAMBIZ, MOKHTARI. (2011). Advanced Risk Management in Offshore Terminals and

Marine Ports. Liverpool John Moores University.

Keliat, Makmur. (2009). Keamanan Maritim Dan Implikasi Kebijakannya Bagi Indonesia. Jurnal Ilmu Sosial dan Ilmu Politik 13(Juli): 19.

Kemenkeu. (2014). Kajian Pengawasan Lalu Lintas Laut Di Indonesia. Retrieved from:

http://www.kemenkeu.go.id/sites/default/files/Kajian Pengawasan Lalu Lintas Laut di Indonesia.pdf.

Kinney, Laureen. (2009). Canada' S Marine Security. Canadian Naval Review 4(4): 15-19.

Kittinger, John N. et al. (2011). Marine Protected Areas, Multiple-Agency Management, and

Monumental Surprise in the Northwestern Hawaiian Islands. Journal of Marine Biology 2011: 1-17.

Li, K. X., and Jin Cheng. (2007). The Determinants of Maritime Policy. Maritime Policy and Management 34(6): 521-33.

Lobo, Victor. (2005). One Dimensional Self-Organizing Maps to Optimize Marine Patrol Activities. Oceans 2005 - Europe 1: 569-72.

Munakata, Toshinori, and Z Pawlak. (1996). "Rough Control Application of Rough Set Theory to Control.” In Fourth European Congress on Intelligent ..., , 209-18. http://cis.csuohio.edu/ munakata/publs/pdf/Aachen96R.pdf.

Namdeo, Jyoti, Naveenkumar J. (2014). Predicting Students Performance Using Data Mining Technique with Rough Set Theory Concepts. International Journal of Advance Research in Computer Science and Management Studies 2(2): 367-73. 
Paget, Steven. (2016). The 'best Small Nation Navy in the World'? The Twenty-First Century Royal New Zealand Navy. Australian Journal of Maritime \& Ocean Affairs 8(3): 230-56.

Parameswaran, Prashanth. (2016). China's Maritime Confrontation With Indonesia Is Not New. The Diplomat. Retrieved from: http://thediplomat.com/2016/03/chinas-maritimeconfrontation-with-indonesia-is-nothing-new/.

Pawlak, Zdzisław. (1998). Rough Set Theory and Its Applications. Journal of Telecommunications and Information Technology 29(7): 7-10. http://www.informaworld.com/openurl?genre=article\&doi=10.1080/019697298125470 \&magic $=$ crossref.

Peterson, Nicole D. (2010). "Choices, Options, and Constraints: Decision Making and

Decision Spaces in Natural Resource Management.” Human Organization 69(1): 54-64. http://0-

apps.webofknowledge.com.catalog.library.colostate.edu/full_record.do?page=10\&qid=1 $\& \log$ event $=$ no\&viewType $=$ fullRecord $\&$ SID $=4$ DJ8PlmFL9eb5g5LbA5\&product $=$ WO S\&doc $=98 \&$ search $\_$mode $=$GeneralSearch.

Pierce, Jonathan J et al. (2017). There and Back Again: A Tale of the Advocacy Coalition Framework. The Policy Studies Journal 45(S1): S13-46.

Pohl, Petra et al. (2015). Fall Risk Awareness and Safety Precautions Taken by Older Community-Dwelling Women and Men-a Qualitative Study Using Focus Group Discussions. PLoS ONE 10(3): 1-16.

Psarros, George Ad, Alexander F. Christiansen, Rolf Skjong, and Gjermund Gravir. (2011). On the Success Rates of Maritime Piracy Attacks. Journal of Transportation Security 4(4): 309-35.

Rabbani, Masoud, and Seyyed Mostafa Bahadornia. (2013). A Hierarchical Fuzzy Portfolio Selection Process Considering Transaction Costs with a Hybrid Intelligent Algorithm. 4(September): 90-108.

Ramos, Jorge, Miguel Tiago Oliveira, and Miguel N. Santos. (2011). Stakeholder Perceptions of Decision-Making Process on Marine Biodiversity Conservation on Sal Island (Cape Verde). Brazilian Journal of Oceanography 59(SPEC. ISSUE 1): 95-105.

Roberts, Christopher. (2017). The South China Sea: Beijing's Challenge to ASEAN and UNCLOS and the Necessity of a New Multi-Tiered Approach. RSIS Working Paper Nanyang Technological University (307): 30. https://dr.ntu.edu.sg/handle/10220/43715.

Siswanto, Rusdi. (2015). The Dilemma of Indonesia's Coast Guard. The Jakarta Post. Retrieved from: http://www.thejakartapost.com/news/2015/02/11/the-dilemmaindonesia-s-coast-guard.html (October 25, 2017).

Szeląg, Marcin, Salvatore Greco, and Roman Słowiński. (2014). Variable Consistency Dominance-Based Rough Set Approach to Preference Learning in Multicriteria Ranking. Information Sciences 277: 525-52.

Tacnet, Jean Marc et al. (2017). New MCDM Methods under Uncertainty Applied to Integrated Natural Risks Management. In 2017 IEEE International Conference on Computational Intelligence and Virtual Environments for Measurement Systems and Applications, CIVEMSA 2017 - Proceedings, , 193-98. 
Tarmidi, Zakri M et al. (2014). Issues and Challenges in Managing Malaysia' S Marine Spatial Information Sharing. (Boateng 2006): 1-8.

Weible, Christopher, and Paul Sabatier. (2007). A Guide to Advocacy Coalition Framework.

In Handbook of Public Policy Analysis, , 123-36.

Yang, Qiang, Ping-an Du, Yong Wang, and Bin Liang. (2017). A Rough Set Approach for Determining Weights of Decision Makers in Group Decision Making. Plos One 12(2): e0172679. http://dx.plos.org/10.1371/journal.pone.0172679.

Yang, Z. L., J. Wang, S. Bonsall, and Q. G. Fang. (2009). Use of Fuzzy Evidential Reasoning in Maritime Security Assessment. Risk Analysis 29(1): 95-120.

Zhou, Deyun et al. (2017). A New Weighting Factor in Combining Belief Function. PLoS ONE 12(5): 1-21. http://dx.doi.org/10.1371/journal.pone.0177695. 